\title{
Sobrevivência de Operárias de Atta sexdens rubropilosa Forel (Hymenoptera: Formicidae) Isoladas do Formigueiro e Alimentadas com Dietas Artificiais
}

\author{
Odair C. Bueno ${ }^{1}$, Maria S.C. Morini ${ }^{1}$, Fernando C. Pagnocca ${ }^{1}$, Maria J.A. Hebling ${ }^{1}$ e \\ Osvaldo A. Silva ${ }^{1}$ \\ ${ }^{1}$ UNESP, Instituto de Biociências, Centro de Estudos de Insetos Sociais (CEIS), \\ Caixa postal 199, 13.506-900, Rio Claro, SP.
}

An. Soc. Entomol. Brasil 26(1): 107-113 (1997)

Survival of Workers of Atta sexdens rubropilosa Forel (Hymenoptera: Formicidae) Isolated from the Ant-Nest and Fed Artificial Diets

\begin{abstract}
Artificial diets, were studied for medium sized workers of Atta sexdens rubropilosa Forel isolated from laboratory and natural ant-nests. The bioassays were undertaken with 6 ants/Petri dish, 10 dishes/test, in an environmental chamber at $24 \pm 1{ }^{\circ} \mathrm{C}$ and $70 \% \mathrm{RH}$. The number of dead ants/dish was observed daily. Results showed that there was no difference among the laboratory and field workers when treated with the liquid artificial diet. The same was demonstrated when we compared the liquid diet to the solid one. Results demonstrated that the artificial solid diet, changed every 48 hours up to 25 days, was a suitable alternative to work medium sized workers of $A$. sexdens rubropilosa, isolated from the ant-nest in laboratory bioassays.
\end{abstract}

KEY WORDS: Insecta, Attini, artificial diet, ant, bioassays.

RESUMO - Avaliou-se dietas artificiais, para operárias médias de Atta sexdens rubropilosa Forel isoladas de formigueiros de laboratório e de campo. Os bioensaios foram realizados com 6 formigas/placa de Petri, sendo 10 placas/tratamento, em câmara ambiental a $24 \pm 1{ }^{\circ} \mathrm{C}$ e UR $>70 \%$. Não houve diferença na sobrevivência entre as operárias de laboratório e de campo, quando tratadas com dieta artificial líquida. Ao se comparar as dietas artificiais líquida e sólida, pode-se constatar que não houve diferença na sobreviência das operárias de laboratório tratadas com as diferentes dietas. A dieta artificial sólida com troca a cada $48 \mathrm{~h}$, até 25 dias, representa uma alternativa para se trabalhar com operárias médias de $A$. sexdens rubropilosa, isoladas do formigueiro, em bioensaios de laboratório.

PALAVRAS-CHAVE: Insecta, Attini, dieta artificial, formiga, bioensaio.

As relações trófícas entre as espécies de Attini são complexas e a herbivoria que exercem sobre diferentes tipos de plantas, a relação mutualística com o fungo que cultivam e a própria estrutura social dificultam os estudos sobre esses insetos. Geralmente, os estudos sobre biologia, ecologia, etologia e controle de formigas do gênero Atta são realizados no 
campo ou em formigueiros mantidos em laboratório, aos quais é oferecido, regularmente, material vegetal fresco (Bueno et al. 1990).

A literatura registra poucas informações a respeito da sobrevivência de formigas cortadeiras isoladas do formigueiro e mantidas com dieta artificial. Poucas dietas têm sido utilizadas com sucesso, pois, além de não manterem as formigas por um tempo suficiente para os ensaios, podem ser de difícil preparo. Com o conhecimento de que a maior parte dos nutrientes utilizados pelos indivíduos são provenientes da seiva da planta (Littledyke \& Cherrett 1976), ou seja, apenas $5 \%$ da necessidade energética dos adultos provém do fungo (Cherrett 1980), testou-se a possibilidade de se manter as operárias do gênero Atta isoladas do restante do formigueiro, o que poderá ser útil para estudos específicos sobre a toxicidade e modo de ação de extratos vegetais, produtos químicos e agentes biológicos.

Como a realização de bioensaios com qualquer inseto exige uma alimentação que os mantenha vivos por um determinado período, foram feitas tentativas por Howard et al. (1988) que trataram operárias de Atta cephalotes (L.) com dieta artificial desenvolvida por Boyd \& Martin (1975), e por Löeck \& Rosenthal (1990) que utilizaram solução aquosa de mel, para manterem vivas operárias de Atta sexdens piriventris Santschi.

O objetivo desse trabalho foi estabelecer uma dieta artificial de composição simples, de fácil preparo e manipulação, para a manutenção de operaras adultas de Atta sexdens rubropilosa Forel, isoladas do formigueiro, bem como uma técnica para melhorar a sobrevivência de formigas em condições adequadas, para a realização de bioensaios em laboratório.

\section{Material e Métodos}

Inicialmente foi testada uma dieta artificial, na forma líquida, para formigas originárias de formigueiros de laboratório e de campo e, em seguida, na forma sólida. Para tanto, operárias médias de $A$. sexdens rubropilosa, com peso entre 10 e $20 \mathrm{mg}$ e largura da cápsula cefálica entre 2,0 e 2,8 mm, foram coletadas de formigueiros mantidos em laboratório por, aproximadamente, cinco anos. Os formigueiros foram supridos diariamente com folhas de Eucalyptus alba e, semanalmente, com outras plantas palatáveis às saúvas, como Hibiscus rosa-sinensis e Ligustrum lucidum. Para a realização dos bioensaios, as formigas foram colocas em placas de Petri $(10 \times 1,5 \mathrm{~cm})$ e mantidas em câmara ambiental à $24 \pm 1{ }^{\circ} \mathrm{C}$ com> $70 \%$ de UR. Em cada série experimental foram utilizadas 10 placas de Petri forradas com papel filtro, contendo 6 formigas/placa (Morini 1995). As observações foram feitas a cada 24 $\mathrm{h}$, registrando-se o número de formigas mortas em cada placa.

A dieta foi composta de: $5 \%(\mathrm{p} / \mathrm{v})$ de glicose, $1 \%$ de peptona bacteriológica e $0,1 \%$ de extraio de levedura (produtos da Difco), dissolvidos em $100 \mathrm{ml}$ de água destilada e, após a mistura, levados ao forno de microondas por 6 min para a solubilização dos componentes. Logo após, a dieta foi distribuída em tubos de ensaio $(20 \times 2 \mathrm{~cm})$, autoclavada por $15 \mathrm{~min}$ a $120{ }^{\circ} \mathrm{C}$ e $1 \mathrm{~atm}$ de pressão e, posteriormente, conservada em geladeira. No interior de cada placa de Petri foi introduzida uma tampa plástica de $1,8 \mathrm{~cm}$ de diâmetro, preenchida com algodão hidrófilo, o qual foi umedecido com 1,5 $\mathrm{ml}$ da dieta líquida ou água. Foram preparadas quatro séries experimentais com 10 repetições controle, i.e., apenas formigas colocadas no inteior das placas; controle com água, i.e., as formigas receberam apenas água, com troca diária; as formigas receberam dieta artificial líquida com troca diária, e as formigas receberam dieta artificial líquida com troca a cada 48 h. As mesmas sequências experimentais foram realizadas com operárias de tamanho semelhante, coletadas de trilhas de um sauveiro de campo de A. sexdens rubropilosa, localizado no Campus do Instituto de Biociências UNESP, Rio Claro, SP.

Após a obtenção dos resultados do experimento já relacionado, realizou-se uma outra sequiência experimental com a finalidade de 
testar a mesma dieta, porém na forma sólida. Assim para esse bioensaio foi acrescentado 1,5\% de ágar bacteriológico (Difco) e, após a esterilização, o material foi vertido nas placas de Petri formando camada de $0,5 \mathrm{~mm}$ de espessura. Foram prepraradas quatro séries experimentais com 10 repetições, apenas com formigas coletadas de formigueiro de laboratório que receberam: controle, i.e., dieta líquida, com troca a cada $48 \mathrm{~h}$; dieta sólida, com troca a cada $48 \mathrm{~h}$; dieta sólida e água embebida em algodão hidrófilo, com troca a cada 24 h; e dieta sólida e água embebida em algodão hidrófilo, com troca a cada $48 \mathrm{~h}$. A dieta sólida foi oferecida em pedaços de, aproximadamente $0,5 \mathrm{~g}$ e a dieta líquida foi a mesma quantidade 1 usada anteriormente $(1,5 \mathrm{ml})$.

As curvas de sobrevivência foram elaboradas a partir das percentagens de ocorrência de formigas vivas por dia, no conjunto das 10 placas. Dos valores observados por placa, também foi determinada a média da sobrevivência do tratamento. Posteriormente, foi verificada a adequação dos dados à distribuição de Weibull, com conseqüente estimação da longevidade média populacional e o parâmetro de forma (Haddad et al. 1995). A primeira corresponde a uma estimativa do valor médio populacional desde que os dados atendam a distribuição de Weibull. O segundo indica a forma da curva de sobrevivência, ou seja, se a população tem uma relação de sobrevivência do Tipo I, onde $\alpha>1$ : o índice de mortalidade aumenta com o tempo; do Tipo II, onde $\alpha=1$ : o índice de mortalidade é constante no tempo, e do Tipo III, onde $\alpha<1$ : o índice de mortalidade diminui com o tempo (Sgrillo 1982). Finalmente, a comparação de múltiplas curvas de sobrevivência foi realizada segundo Cox \& Oakes (1984).

\section{Resultados e Discussão}

Os resultados da comparação entre formigas originárias de formigueiros de laboratório e de campo, tratadas com dieta líquida, mostraram que menos de $5 \%$ das formigas, independente da origem, sobreviveram mais que
25 dias (Fig. 1), sendo que as sobrevivências médias também não demonstraram diferenças significativas $(Z=0,057 ; \mathrm{P}>0,47)$. A comparação entre as sobrevivências totais dessas amostras, através do teste de Cox, resultou em 1,603; P > 0,07. A longevidade média da população e o parâmetro de forma, estimados pela distribuição de Weibull, mostram diferenças significativas entre os tratamentos, de acordo com a origem das formigas, ou seja, houve diferença entre as médias de sobrevivência das operárias que não receberam qualquer dieta, daquelas que foram mantidas somente com água e também das que receberam dieta artificial líquida. Entretanto, não houve diferença entre os tratamentos onde ocorreu a troca da dieta a cada $24 \mathrm{~h}$ ou $48 \mathrm{~h}$ (Tabela 1 ).

Os resultados da longevidade e do parâmetro de forma estimados pela distribuição de Weibull para operárias de A. sexdens rubropilosa, relacionados à comparação das dietas líquida e sólida (Tabela 2), demonstram que não houve diferença significativa entre as duas dietas analisadas, verificada através da comparação das curvas de sobrevivência para várias amostras (cinco tratamentos, $\dot{\div}^{2}=7,38$; $\mathrm{gl}=4 ; \mathrm{P}>0,1)$. As curvas de sobrevivência também demonstram que, novamente, menos de $5 \%$ das formigas sobreviveram mais de 25 dias (Fig. 2). Da mesma forma, os resultados observados mostram a adequação da distribuição de Weibull para análise da sobrevivência de insetos, através da análise do parâmetro de forma e da longevidade média, corroborando Sgrillo (1982).

Os resultados obtidos e as observações realizadas indicam que a manipulação fácil, bem como uma menor contaminação por fungos contribuíram para que, a dieta artificial sólida, com troca a cada $48 \mathrm{~h}$, represente a melhor opção para os bioensaios de laboratório com operárias médias de A. sexdens rubropilosa. A mesma dieta, na forma líquida, pode também ser usada sempre que os testes a serem realizados envolvam substâncias solúveis em água. Os bioensaios poderão ser realizados até o $25^{\circ}$ dia, já que a partir desse momento apenas $5 \%$ das formigas se mantém vivas nas placas de Petri. 

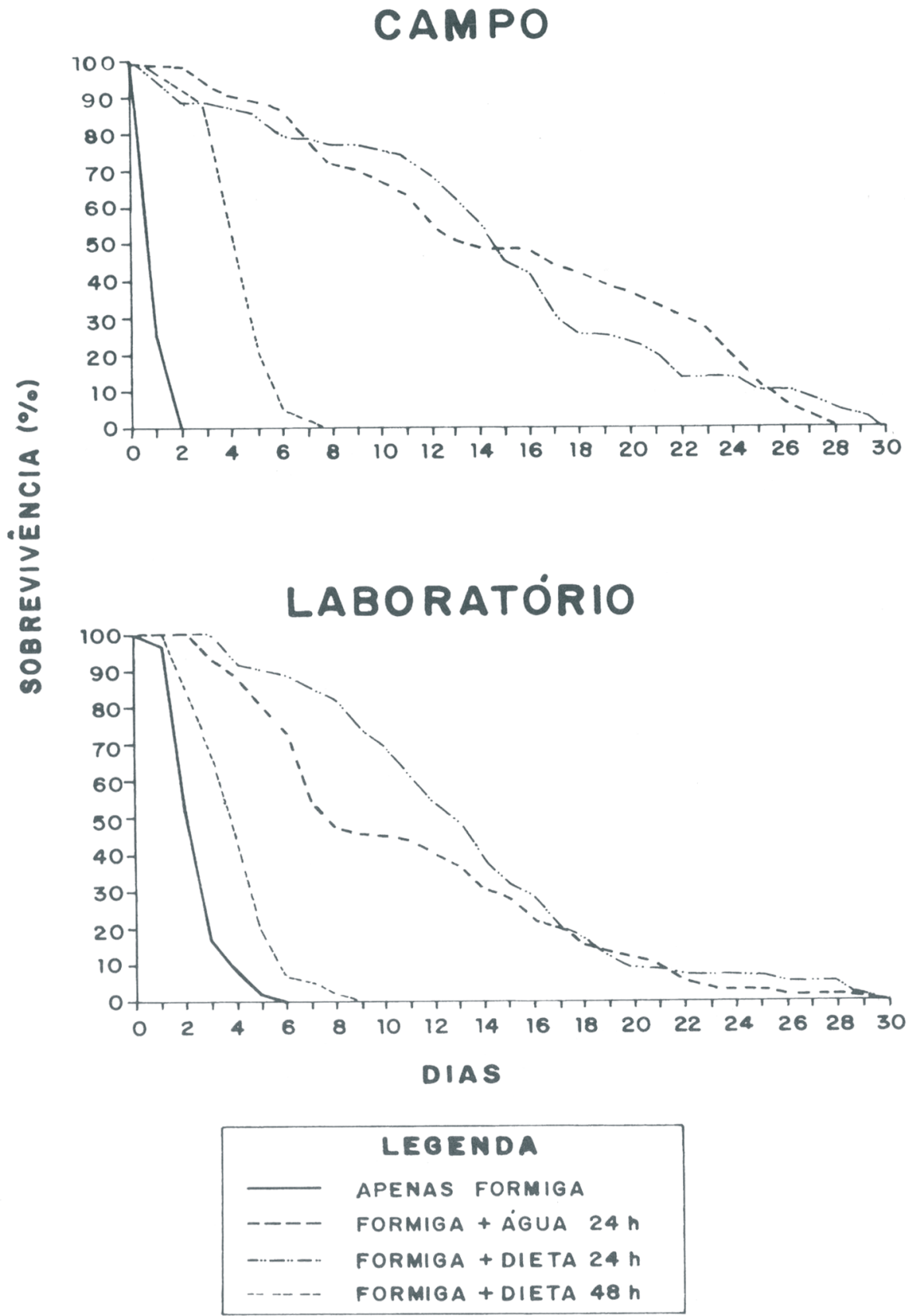

Figura 1. Curvas de sobrevivência de operárias de Atta sexdens rubropilosa provenientes de formigueiros de campo e laboratório, submetidas a diferentes dietas $(\mathrm{n}=80)$. 
Tabela 1. Longevidade (em dias) e parâmetro de forma, estimados pela distribuição de Weibull, para operárias de Atta sexdens rubropilosa, submetidas a diferentes dietas fora do ninho $(\mathrm{n}=80)$.

\begin{tabular}{llccc}
\hline Origem das formigas & Tratamento & Longevidade & Cox $^{1}$ & $\alpha$ \\
\hline \multirow{2}{*}{ Campo } & Somente & 0,7 & a & 1,56 \\
& formiga & 4,0 & $\mathrm{~b}$ & 2,63 \\
& Água & 11,7 & $\mathrm{c}$ & 1,37 \\
& Dieta (24h) & 13,7 & $\mathrm{c}$ & 1,50 \\
& Dieta (48h) & & & 2,93 \\
Loboratório & Somente & 2,5 & $\mathrm{a}$ & \\
& formiga & 3,8 & $\mathrm{~b}$ & 2,33 \\
& Água & 12,8 & $\mathrm{c}$ & 2,22 \\
& Dieta (24h) & 10,7 & $\mathrm{c}$ & 1,73 \\
\hline
\end{tabular}

${ }^{1}$ Letras diferentes indicam diferença significativa pelo teste de Cox $(\mathrm{P}<0,05)$.

Howard et al. (1988) testando a ação de terpenóides deterrentes sobre operárias de $A$. cephalotes, em condições de laboratório, observaram que as formigas sobreviveram no máximo 10 dias, quando mantidas com dieta artificial líquida desenvolvida por Boyd \& Martin (1975), composta de 9\% de glicose, $1 \%$ de peptona bacteriológica e $0,1 \%$ de complexo vitaminico. Löeck \& Rosenthal (1990) cons- tataram que as operárias de A. sexdens piriventris sobreviveram até 8 dias quando mantidas com solução aquosa de mel a $10 \%$.

Comparando-se os resultados com os dados citados na literatura, é possível obter uma sobrevivência superior das formigas tratadas com a dieta proposta, tanto na forma líquida como sólida, pois em alguns casos foram observadas sobrevivência de 28 a 30

Tabela 2. Longevidade (em dias) e parâmetro de forma, estimados pela distribuição de Weibull, para operárias de Atta sexdens rubropilosa, mantidas em dietas artificiais líquida e sólida $(\mathrm{n}=40)$.

\begin{tabular}{lcc}
\hline Tratamento & Longevidade & $\alpha$ \\
\hline $\begin{array}{l}\text { Dieta líquida } \\
(48 \mathrm{~h})\end{array}$ & 10,4 & 1,35 \\
$\begin{array}{l}\text { Dieta sólida } \\
(24 \mathrm{~h})\end{array}$ & 12,9 & 1,51 \\
$\begin{array}{l}\text { Dieta sólida } \\
(48 \mathrm{~h})\end{array}$ & 12,3 & 1,63 \\
$\begin{array}{l}\text { Dieta sólida } \\
+ \text { água (24h) }\end{array}$ & 11,5 & 2,05 \\
$\begin{array}{l}\text { Deita sólida } \\
+ \text { água (48h) }\end{array}$ & 13,0 & 2,03 \\
\hline
\end{tabular}


dias, com média de 10,7 e 13,2 dias (dieta líquida e dieta sólida + água, respectivamente) quando trocadas a cada $48 \mathrm{~h}$. Também é impor- tante ressaltar que as dietas e técnicas estabelecidas neste trabalho têm sido usadas com sucesso em bioensaios sobre toxicidade de

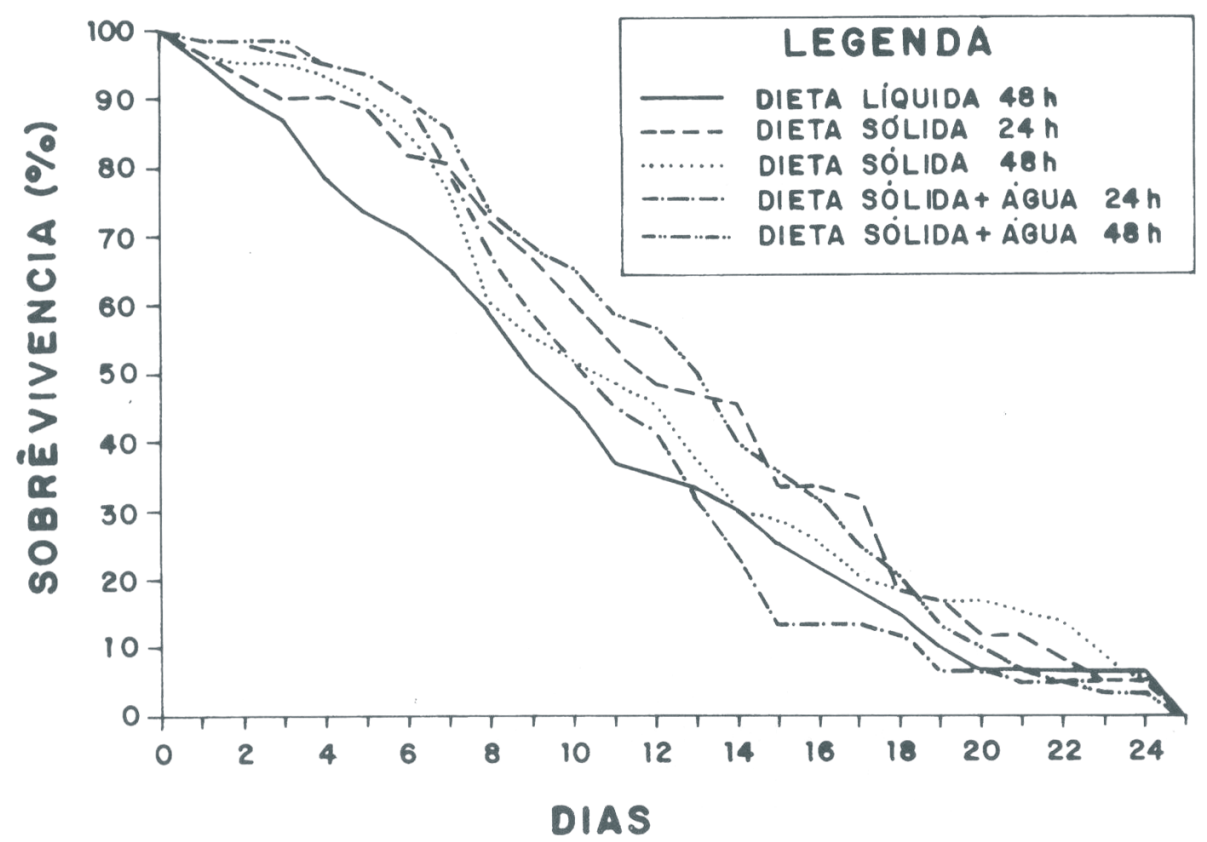

Figura 2. Curvas de sobrevivência de operárias de Atta sexdens rubropilosa mantida com dietas artificiais líquida e sólida $(n=40)$.

extratos orgânicos de folhas de Ricinus communis (Bigi 1994), de Canavalia ensiformis (M.F.M.A. Bigi informação pessoal) e de sementes de Sesamum indicum (Morini 1995) para operárias de A. sexdens rubropilosa, em laboratório.

\section{Agradecimentos}

Ao Dr. Antônio C.S. Pião pela colaboração nas análises estatísticas; à FAPESP (Proc. 90/ 3527-6) e ao CNPq (Proc. 208/91 -7), pelos auxílios concedidos.

\section{Literatura Citada}

Bigi, M.F.A.M. 1994. Efeitos de extratos o gânicos foliares de Ricinus communis L. sobre operárias de Atta sexdens rubropilosa Forel, 1908 (Hymenoptera: Formicidae). Tese de mestrado, UNESP, Rio Claro, 147p.

Boyd, N.D. \& M.M. Martin. 1975. Faecal proteinases of the fungus-growing ant Atta texana: their fungai origin and ecological signifícance. J. Insect Physiol. 21: 1815-1820. 
Bueno, O.C., MJ. Hebling-Beraldo, O. Aulino da Silva, F. Pagnocca, J.B. Fernandez \& P.C. Vieira. 1990. Toxic effect of plants on leaf-cutting ants and their symbiotic fungus, p. 420-426. In R.K. Jaffe \& K.A. Cedeno (eds), Applied Myrmecology: a world perspective. São Francisco, Westview Press, 740p.

Cherrett, J.M. 1980. Possible reasons for the mutualism between leaf-cutting ants (Hymenoptera: Formicidae) and their fungus. Biol. Ecol. Mediter. 7: 113-122.

Cox, D.R. \& D. Oakes. 1984. Analysis of survival data. 1rd ed, Chapman \& Hall, London,201p.

Haddad, M.L., R.C.B. Moraes \& J.R.P. Parra. 1995. Modelos bioestatísticos aplicados à entomologia. Universidade São Paulo, ESALQ, Piracicaba, 44p.

\section{Howard, J.J., T.P. Green \& D.F. Wiemer.} 1988. Comparative deterrency of two terpenoids to two genera of attine ants. J. Chem.Ecol.15:2279-2288.
Littledyke, M. \& J. Cherrett. 1976. Direct ingestion of plant sap from cut leaves by the cutting ants Atta cephalotes (L.) and Acromyrmex octospinosus (Reich) (Hymenoptera: Formicidae). Bull. Entomol. Res. 66:205-217.

Löeck, A.E. \& M.D'.A. Rosenthal. 1990. Sobrevivência de operárias de Atta sexdens piriventris (Hymenoptera: Formicidae) na presença de substratos líquidos. Ciênc. Cult. 42:990-992.

Morini, M.S.C. 1995. Toxicidade de extratos orgânicos da semente do gergelim (Sesamum indicum DC.) sobre operárias de Atta sexdens rubropilosa Forel, 1908 (Hymenoptera: Formicidae). Tese de doutorado, UNESP, Rio Claro, 117p.

Sgrillo, R.B. 1982. A distribuição de Weibull como modelo de sobrevivência de insetos. Ecossistema 7: 9-13.

Recebido em 21/03/96. Aceito em 12/02/97. 